\title{
Outcomes After Open and Endovascular Repair of Non-Ruptured True Pancreaticoduodenal and Gastroduodenal Artery Aneurysms Associated with Coeliac Artery Compression: A Multicentre Retrospective Study
}

\author{
Giulio Illuminati $^{a,+}$, Aurélien Hostalrich ${ }^{b, \ddagger}$, Rocco Pasqua ${ }^{a}$, Priscilla Nardi ${ }^{a}$, Xavier Chaufour ${ }^{b}$, Jean-Baptiste Ricco ${ }^{c, *}$ \\ ${ }^{a}$ Department of Surgical Sciences, University of Rome - La Sapienza, Rome, Italy \\ ${ }^{\mathrm{b}}$ Department of Vascular Surgery, University Hospital Rangueil, Toulouse, France \\ ${ }^{c}$ Department of Clinical Research, University Hospital of Poitiers, Poitiers, France
}

\section{WHAT THIS PAPER ADDS}

Aneurysms of the pancreaticoduodenal arcades including the gastroduodenal artery (PDAAs) are rare, and best treatment evidence is lacking. This multicentre study suggests that in patients with PDAAs and compression of the coeliac axis (CA) by a median arcuate ligament (MAL), the choice between transcatheter embolisation or open exclusion of PDAAs should be tailored according to the location of the aneurysm, favouring open surgical repair for aneurysms located on the gastroduodenal and anterior pancreaticoduodenal arteries and embolisation for aneurysms located on the posterior pancreaticoduodenal artery. This study also demonstrates that in this setting CA stenting should be avoided.

Objective: True aneurysms of the peri-pancreatic arcade (PDAA) have been attributed to increased collateral flow related to coeliac axis (CA) occlusion by a median arcuate ligament (MAL). Although PDAA exclusion is currently recommended, simultaneous CA release and the technique to be used are debated. The aim of this retrospective multicentre study was to compare the results of open surgical repair of true non-ruptured PDAA with release or CA bypass (group A) vs. coil embolisation of PDAA and CA stenting or laparoscopic release (group B).

Methods: From January 1994 to February 2019, 57 consecutive patients (group A: 31 patients; group B: 26 patients), including $35(61 \%)$ men (mean age $56 \pm 11$ years), were treated at three centres. Twenty-six patients (46\%) presented with non-specific abdominal pain: $15(48 \%)$ in group A and $11(42 \%)$ in group B $(p=.80)$.

Results: No patient died during the post-operative period. At 30 days, all PDAAs following open repair and embolisation had been treated successfully. In group $A$, all CAs treated by MAL release or bypass were patent. In group B, 2/12 CA stentings failed at $<48$ hours, and all MAL released by laparoscopy were successful. Median length of hospital stay was significantly greater in group A than in group B (5 vs. 3 days; $p=.001)$. In group $A$, all PDAAs remained excluded. In group $B$, three PDAA recanalisations following embolisation were treated successfully (two redo embolisations and one open surgical resection). At six years, Kaplan-Meier estimates of freedom for PDAA recanalisation were $100 \%$ in group A, and $88 \% \pm 6 \%$ in group B $(p=.082)$. No PDAA ruptured during follow up. In group A, all 37 CAs treated by MAL release were patent, and one aortohepatic bypass occluded. In group B, five CAs occluded: four after stenting and the other after laparoscopic MAL release with two redo stenting and three aortohepatic bypasses. Estimates of freedom from CA restenosis/occlusion were $95 \% \pm 3 \%$ for MAL release or visceral bypass, and $60 \% \pm 9 \%$ for CA stenting $(p=.001)$. Two late restenoses following CA stenting were associated with PDAA recanalisation. Conclusion: Current data suggest that open and endovascular treatment of PDAA can be performed with excellent post-operative results in both groups. However, PDAA embolisation was associated with few midterm recanalisations and CA stenting with a significant number of early and midterm failures.

Keywords: Embolisation, Median arcuate ligament, Pancreaticoduodenal artery, Visceral aneurysm

Article history: Received 7 September 2020, Accepted 16 February 2021, Available online 21 March 2021

(c) 2021 European Society for Vascular Surgery. Published by Elsevier B.V. All rights reserved.

\footnotetext{
¥ Joint first authors

* Corresponding author. Bâtiment AGORA, CHU de Poitiers, 2 rue de la Milétrie, Poitiers, 86021, France.

E-mail address: jean.baptiste.ricco@univ-poitiers.fr (Jean-Baptiste Ricco).

1078-5884/@ 2021 European Society for Vascular Surgery. Published by Elsevier B.V. All rights reserved.

https://doi.org/10.1016/j.ejvs.2021.02.023
}

\section{INTRODUCTION}

Aneurysms of the peri-pancreatic arteries, including the gastroduodenal artery and its pancreaticoduodenal branches (PDAA), account for only $2 \%-3.5 \%$ of all visceral 
aneurysms. ${ }^{1-3}$ They occur as either true or pseudoaneurysms secondary to pancreatitis or trauma. This study was limited to true PDAAs (Fig. 1) associated with coeliac axis (CA) stenosis by a median arcuate ligament (MAL). ${ }^{4-6}$

Despite their low incidence, these aneurysms deserve attention because, compared with other visceral aneurysms, they rupture at a disproportionate rate at a diameter sometimes $<10 \mathrm{~mm} \cdot{ }^{2,7,8}$ For this reason, irrespective of size, prompt treatment is indicated. ${ }^{2,9}$ For emergency cases, endovascular PDAA embolisation is the preferred technique. ${ }^{8}$ However, with the widespread adoption of endovascular techniques, many intact PDAAs associated with CA stenosis are now treated electively by coil embolisation without CA release, or CA release by laparoscopy or CA stenting. ${ }^{10-12}$ The authors of this study, who are accustomed to performing both open and endovascular techniques for visceral aneurysm repair, have different opinions regarding these techniques. Although all have agreed to perform transcatheter embolisation in the event of PDAA rupture, views on the management of unruptured PDA have been more divided. The literature on this aspect is not particularly helpful, as it consists essentially of case reports or small heterogeneous series mixing true PDAAs with false or ruptured aneurysms, and characterised by poor follow up, and lack of granularity. Hence, the authors of this report have pooled data from their centres to compare the results of open surgical repair of true PDAA with CA release or bypass vs. PDAA embolisation with laparoscopic release of MAL or CA stenting.

\section{METHODS}

From January 1994 to February 2019, 57 consecutive patients, 35 (61\%) of whom were men, with a mean age of 56 \pm 11 years presenting with an unruptured true PDAA associated with CA stenosis by MAL were analysed retrospectively in three academic centres: one in Italy (University of Rome, La Sapienza) and two in France (University Hospital of Poitiers and University Hospital of Toulouse). Each hospital's Institutional Review Board approved the study. Owing to its retrospective nature, patient consent was waived and, according to European Union regulations, the database was de-identified.

For the purposes of the analysis, the patients were divided into two groups. In group A, 31 patients underwent open surgical exclusion of PDAA followed by MAL release or CA revascularisation. In group B, 26 patients underwent endovascular repair with PDAA embolisation with laparoscopic release of MAL or CA stenting.

Pre-operative workup consisted of an abdominal ultrasound study and computed tomography angiography (CTA)

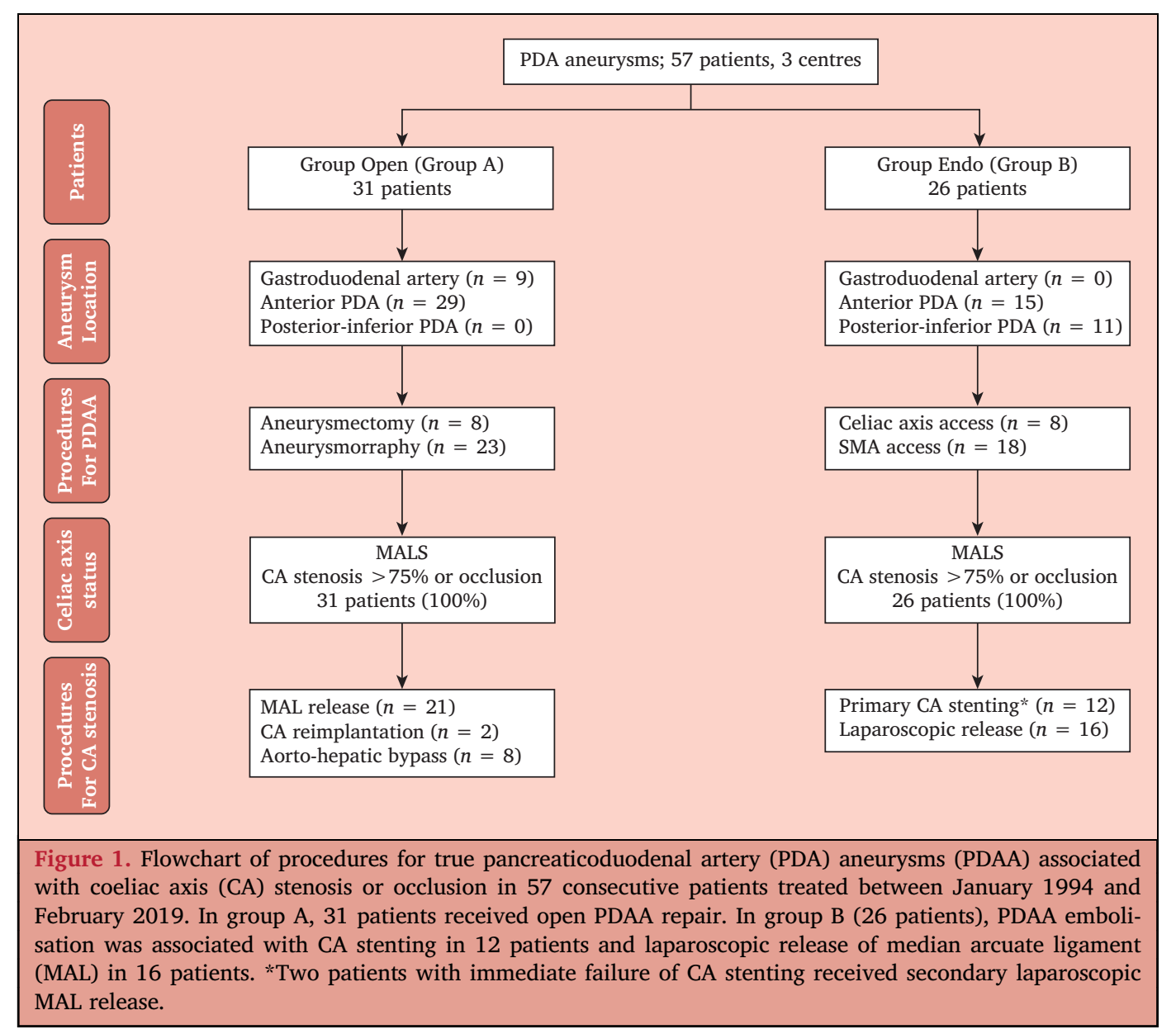


with multiplanar and three dimensional reconstructions associated with a search for focal narrowing of the CA with retrograde filling of the pancreaticoduodenal arteries (Fig. 2). In all cases, pre-operative duplex ultrasound (DUS) evaluated the CA for MAL with inspiratory and expiratory data, which were positive in all cases.

In group $\mathrm{A}(n=31)$, a surgical approach was made through bilateral subcostal incision with median extension toward the xiphoid process or by midline laparotomy. Depending on its size and location (Fig. 3), the PDAA was either resected (aneurysmectomy) with an eventual end to end arterial reconstruction or excluded (aneurysmorrhaphy; Fig. 4). MAL release was performed in 21 patients after gaining control of the coeliac aorta through section of the right crus of the diaphragm (Fig. 5). In the event of fibrosis, or occlusion, and depending on the extent of CA lesions, reimplantation of the CA into the coeliac aorta or revascularisation by an aortohepatic bypass was performed. No peri-pancreatic drainage was carried out.

In group B $(n=26)$, PDAA coil embolisation was achieved with different approaches: percutaneous transfemoral, or transbrachial with coeliac or superior mesenteric artery (SMA) catheterisation. No radial access was used in this series. Catheter configurations consisted primarily of a sheath guiding catheter, a $4 \mathrm{~F}$ catheter, and a microcatheter to achieve exclusion of inflow and outflow vessels, and to reduce the risk of PDAA recanalisation. According to surgeon preference, embolisation was followed by laparoscopic MAL release of or primary CA stenting. For primary stenting, a $4 \mathrm{~F}$ Cobra catheter and a 0.035 inch stiff

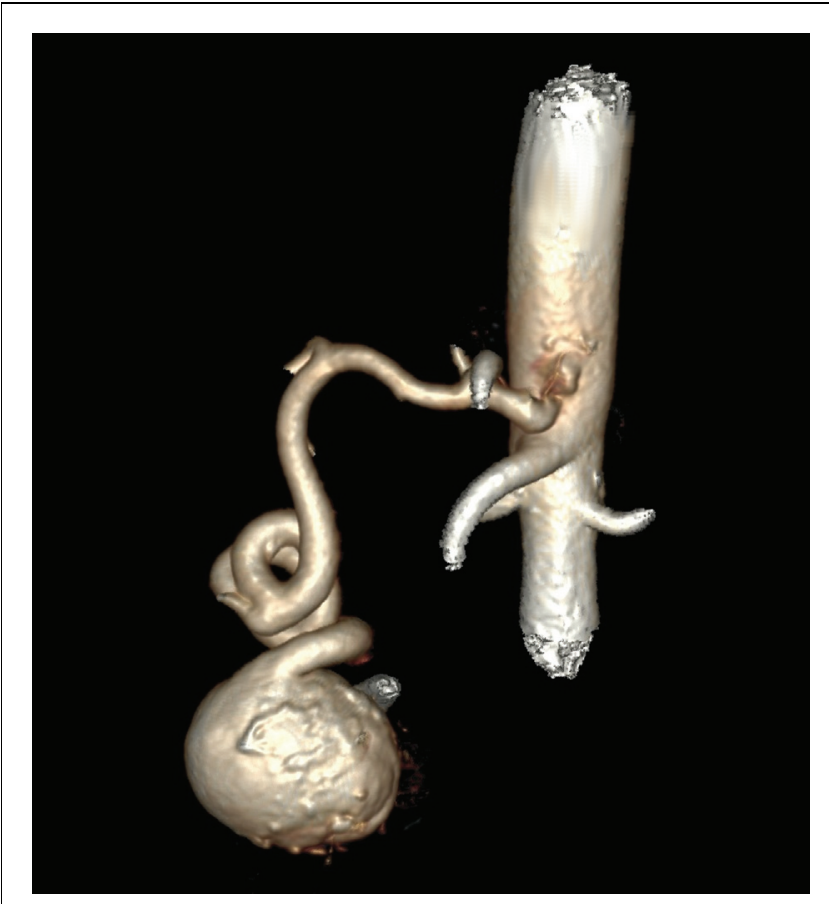

Figure 2. Computed tomography angiography of the aorta and visceral arteries of a patient in a series showing aneurysm of the anterior pancreaticoduodenal artery associated with proximal stenosis of the coeliac axis due to compression of the median arcuate ligament.

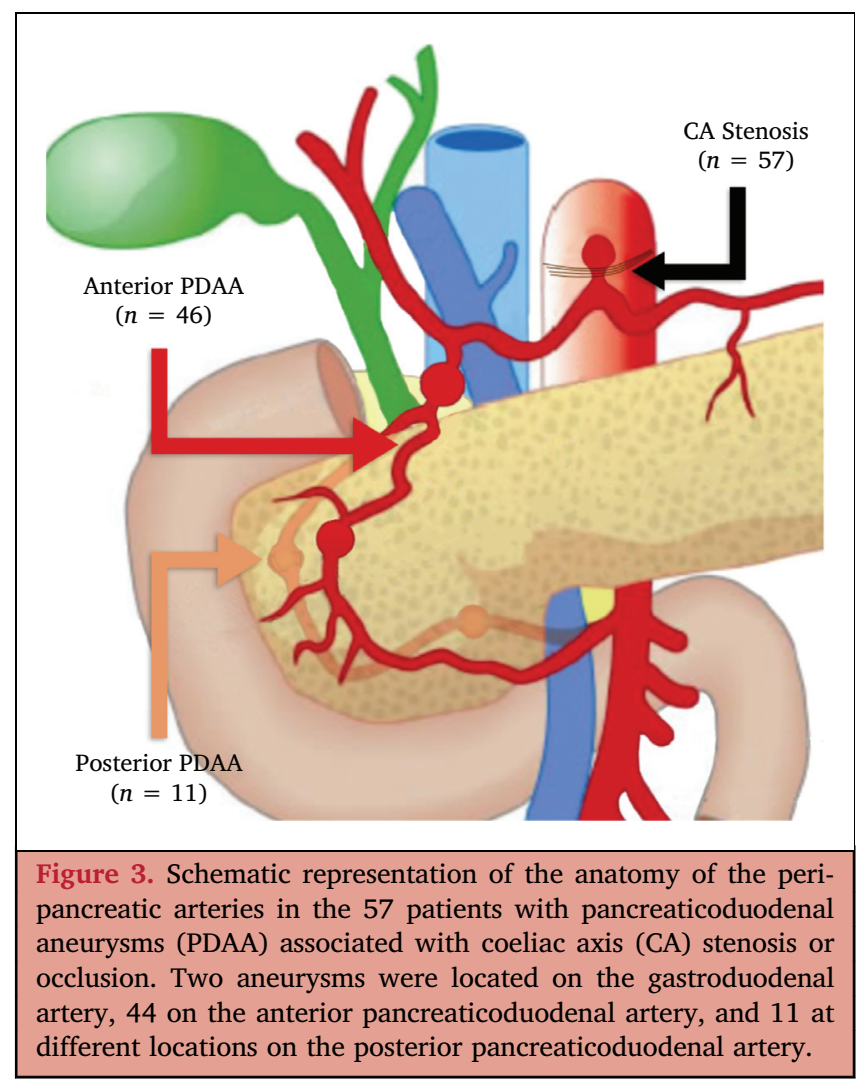

guidewire were used. Angioplasty was achieved by a balloon catheter, followed by deployment of a balloon expandable stent. Laparoscopic MAL release was performed by collaboration with a surgeon familiar with laparoscopic techniques and according to the usual technique described elsewhere. $^{13}$

DUS of the pancreaticoduodenal arteries was performed prior to discharge in all patients. During follow up, all patients were seen on an outpatient basis, at one month and yearly thereafter, with aortic and the visceral artery DUS followed by CTA or preferably MRA after PDAA catheter embolisation if abnormal.

The primary study endpoints were post-operative mortality and morbidity, late PDAA recurrence, and reoperation. Secondary endpoints were post-operative hospital stay and late survival.

In each group, the following parameters were recorded: demographics; symptoms; imaging findings (DUS and CTA); site of PDAA; type of surgery; endovascular access route; SMA or CA catheterisation; embolisation; MAL release; visceral artery revascularisation; any revision; PDAA reperfusion; CA restenosis; morbidity; mortality rate; days in hospital; and median follow up time. All study data were cross checked and independently analysed by the clinical research department of the University of Poitiers.

The study was conducted according to the STROBE recommendations (see Supplementary Material). Univariable analysis was performed using $t$ tests for normally distributed continuous variables and Mann-Whitney rank test for non-normally distributed variables with median and interquartile range (IQR). Fisher's exact test was used for 


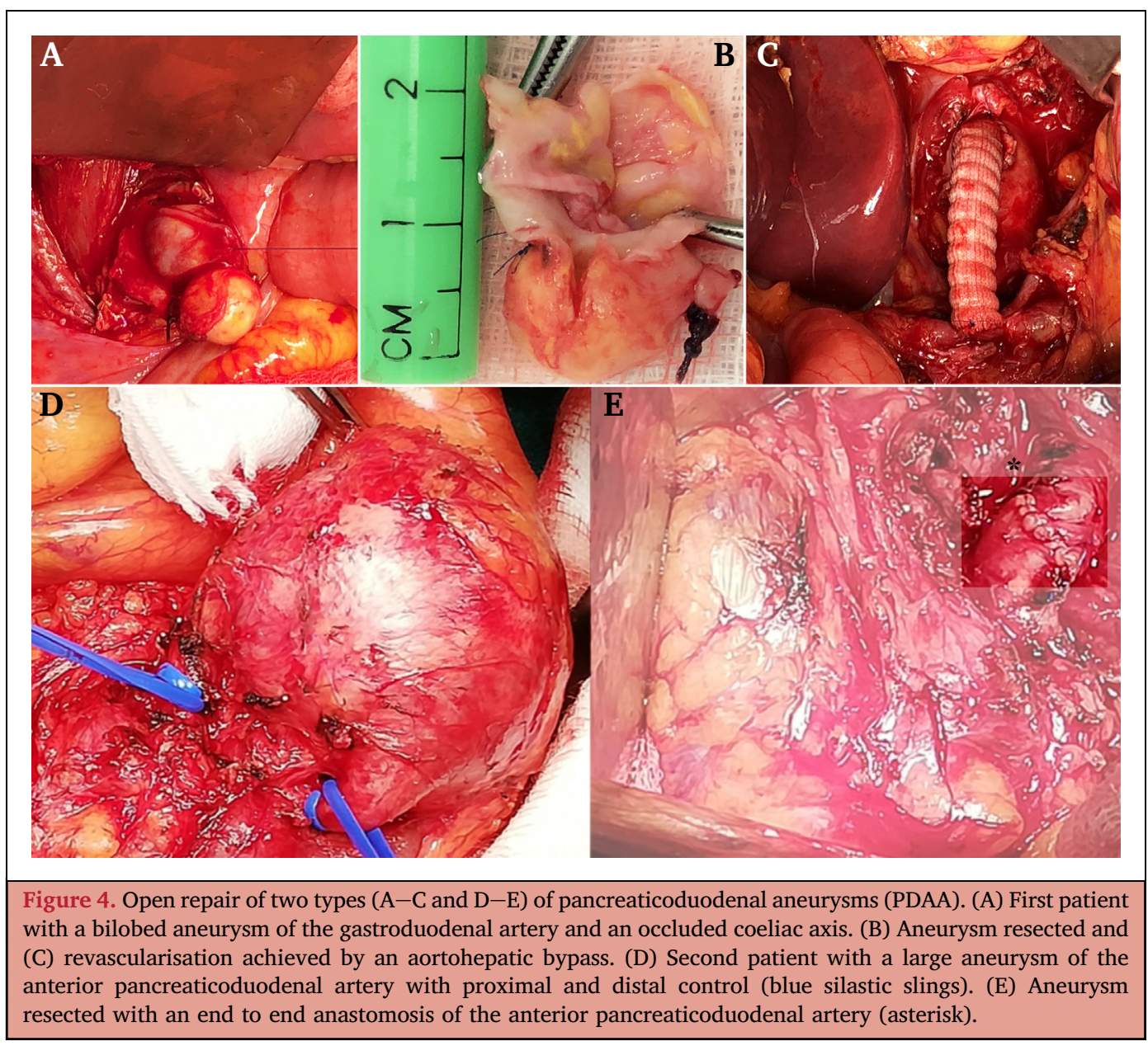

categorical variables. All 30 day outcomes were calculated by standard counts. Midterm outcomes were estimated using the Kaplan-Meier time to event method. A $p$ value $<$ .050 was considered to be statistically significant.

\section{RESULTS}

Between 1994 and 2019, 57 consecutive patients, including 35 men (61\%), with a mean age of $56 \pm 11$ years underwent elective PDAA treatment. At presentation, all PDAAs were intact. No significant differences in baseline characteristics were observed between the two groups (Table 1). Twentysix patients (46\%) presented with non-specific abdominal pain: $15(48 \%)$ in group $A$ and $11(42 \%)$ in group $B(p=.79)$. PDAA location differed between groups (Table 2). All gastroduodenal aneurysms $(n=2)$ were treated by open repair. There were statistically significantly more aneurysms of the anterior pancreaticoduodenal artery in group $A$ than in group $B(94 \%$ vs. $58 \% ; p=.011)$ and all posterior

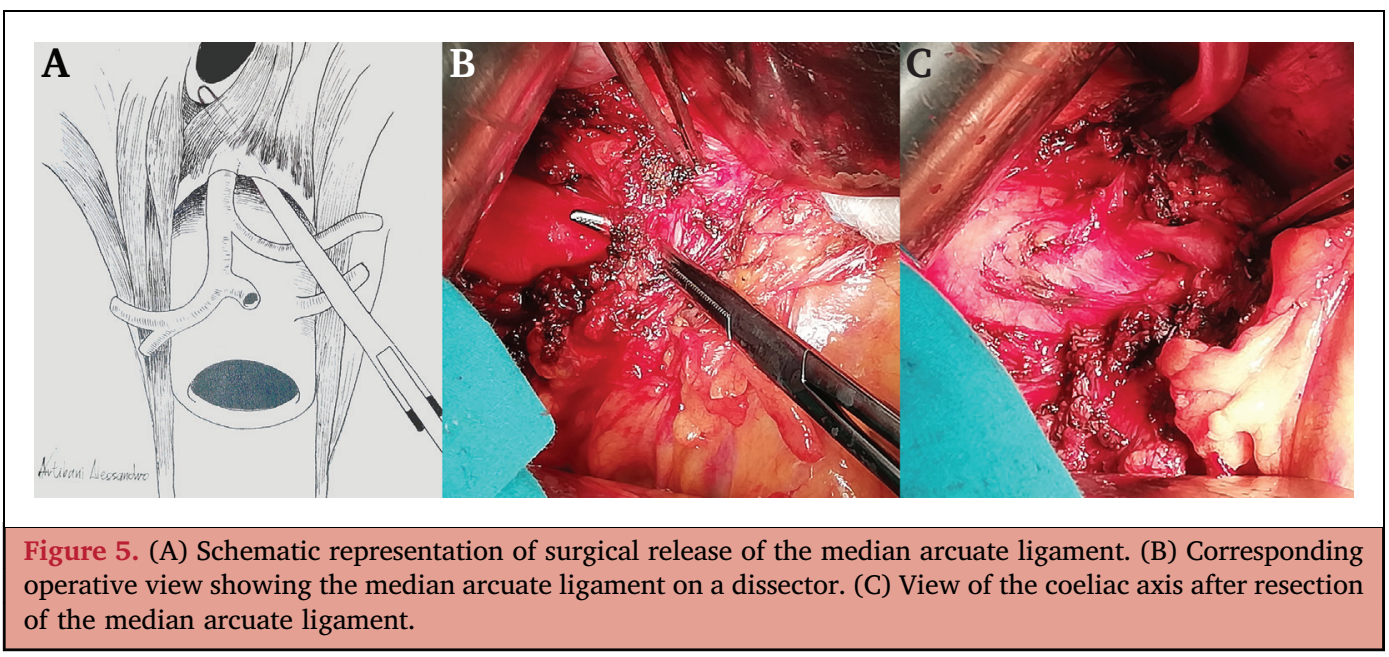




\begin{tabular}{|lllll|}
\hline \multicolumn{5}{|c|}{ Table 1. Demographics, pre-operative cardiovascular risks } \\
and comorbidities in 57 patients with a non-ruptured \\
aneurysm of the pancreaticoduodenal arteries and stenosis \\
or occlusion of the coeliac axis, comparing group A and \\
group B
\end{tabular}

Data are presented as $n(\%)$ or mean \pm standard deviation. ASA $=$ American Society of Anesthesiologists; CAD = coronary artery disease; $\mathrm{COPD}=$ chronic obstructive pulmonary disease; $\mathrm{DM}=$ diabetes mellitus.

* Group A consisted of patients who underwent open surgical repair of pancreaticoduodenal aneurysms (PDAA) and release of median arcuate ligament or coeliac axis (CA) bypass.

${ }^{\dagger}$ Group B consisted of patients who had transcatheter PDAA embolisation with CA stenting or laparoscopic release of the median arcuate ligament.

pancreaticoduodenal artery aneurysms were treated by embolisation. Mean PDAA diameter was $29 \mathrm{~mm}$ (IQR $24-$ $33 \mathrm{~mm})$, PDAA diameters were significantly larger in group A $(32 \pm 8 \mathrm{~mm}$ [IQR $25-36 \mathrm{~mm}])$ than in group B $(27 \pm 6$ $\mathrm{mm}$ [IQR $22-29 \mathrm{~mm}$ ]; $p=.012$ ).

Open procedure details, including MAL release or CA revascularisation, are presented in Table 3 and endovascular procedure details in Table 4 . In group A, aneurysmorrhaphy ( $n=23$ [74\%]) was the preferred technique (aneurysmectomy: $n=8$ [26\%]). CA compression was
Table 3. Open, and laparoscopic procedures in 31 patients of group A with non-ruptured pancreaticoduodenal aneurysm and stenosis or occlusion of the coeliac axis (CA)

\begin{tabular}{|ll|}
\hline $\begin{array}{l}\text { Open repair of the aneurysm with surgical release } \\
\text { of MAL by laparotomy or visceral bypass }\end{array}$ & $\begin{array}{l}\text { Patients } \\
(\boldsymbol{n}=\mathbf{3 1})\end{array}$ \\
\hline $\begin{array}{ll}\text { Pancreaticoduodenal aneurysm } \\
\text { Aneurysmorrhaphy }\end{array}$ & $23(74)$ \\
Aneurysmectomy & $8(26)$ \\
MAL and CA revascularisation & $21(68)$ \\
MAL release & $2(6)$ \\
Re-implantation of the CA to the aorta & $8(26)$ \\
Aortohepatic bypass & $1(3)$ \\
\hline Main outcomes & \\
Aortohepatic bypass occluded
\end{tabular}

Data are presented as $n(\%)$. MAL $=$ median arcuate ligament.

* Two cases of direct arterial reconstruction of the pancreaticoduodenal artery.

${ }^{\dagger}$ Fibrosis at the origin of the CA.

${ }^{\ddagger}$ Extensive fibrosis or occlusion of the CA.

treated by MAL section ( $n=21$ [68\%]) or by revascularisation ( $n=10$ [32\%]) in patients with fibrosis or CA occlusion.

In group B, transfemoral sheath access was used in 17 patients $(65 \%)$, and transbrachial access in nine patients (35\%) with CA or SMA catheterisation. Following successful PDAA embolisation, primary stenting of the CA was attempted in 12 patients with two immediate failures. Laparoscopic MAL release was performed in 16 patients, including two patients with immediate CA stenting failure, and was technically successful in all cases.

\section{Early outcomes}

Post-operative mortality was zero in both groups. Six patients (11\%) presented transitory elevation of serum amylase/lipase concentration: two (6\%) in group A and four $(15 \%)$ in group B $(p=.39)$. Two patients in group A developed an incisional hernia, and three patients in group

\begin{tabular}{|c|c|c|c|c|}
\hline Characteristics & Group A $(n=31)^{*}$ & Group B $(n=26)^{\dagger}$ & $p$ value & Total $(n=57)$ \\
\hline Abdominal pain & $15(48)$ & $11(42)$ & .79 & $26(46)$ \\
\hline Pancreatitis & $1(3)$ & $1(4)$ & .89 & $2(4)$ \\
\hline Diameter of PDAA on CTA $-\mathrm{mm}$ & $32 \pm 8$ & $27 \pm 6$ & .012 & $29 \pm 8$ \\
\hline PDAA location & & & .001 & \\
\hline Gastroduodenal artery & $2(6)$ & $0(0)$ & & $2(4)$ \\
\hline Anterior pancreaticoduodenal artery & $29(94)$ & $15(58)$ & & $44(77)$ \\
\hline Posterior pancreaticoduodenal artery & $0(0)$ & $11(42)$ & & $11(19)$ \\
\hline MAL syndrome & $31(100)$ & $26(100)$ & - & $57(100)$ \\
\hline \multicolumn{5}{|c|}{$\begin{array}{l}\text { Data are presented as } n(\%) . \text { PDAA = pancreaticoduodenal artery aneurysm; CTA = computed tomography angiography; MAL }=\text { median arcuat } \\
\text { ligament. } \\
* \text { Group A consisted of patients who underwent open surgical repair of PDAA and release of median arcuate ligament or coeliac axis (CA) bypass } \\
{ }^{\dagger} \text { Group B consisted of patients who had transcatheter embolisation of PDAA with CA stenting or laparoscopic release of the median arcuat } \\
\text { ligament }\end{array}$} \\
\hline
\end{tabular}




\begin{tabular}{|ll|}
$\begin{array}{l}\text { Table 4. Endovascular procedures in } 26 \text { patients of group B } \\
\text { with non-ruptured pancreaticoduodenal aneurysm and } \\
\text { stenosis or occlusion of the coeliac axis (CA) }\end{array}$ \\
$\begin{array}{l}\text { Embolisation of aneurysm with stenting of CA or } \\
\text { laparoscopic release of MAL }\end{array}$ & $\begin{array}{l}\text { Patients } \\
(\boldsymbol{n}=\mathbf{2 6})\end{array}$ \\
\hline $\begin{array}{l}\text { Pancreaticoduodenal aneurysm } \\
\text { Transfemoral sheath access }\end{array}$ & $17(65)$ \\
Transbrachial sheath access & $9(35)$ \\
CA catheterisation & $8(31)$ \\
SMA catheterisation & $18(69)$ \\
Embolisation & $26(100)$ \\
MAL and CA revascularisation & $12(46)$ \\
CA stenting attempted & $2(8)$ \\
Stenting occluded within 48 h & $10(38)$ \\
Stented CA patent at 30 d & $16(62)$ \\
Laparoscopic release of MAL & \\
Main outcomes & $3(11)$ \\
Pancreaticoduodenal aneurysm recanalisation & $5(19)$ \\
Late failure of CA stenting or MAL release by \\
laparoscopy
\end{tabular}

Data are presented as $n(\%)$. MAL $=$ median arcuate ligament; SMA = superior mesenteric artery.

* Coil embolisation of aneurysm's afferent and efferent arteries.

${ }^{\dagger}$ Including two patients with immediate CA stenting failure.

¥ Three redo procedures: redo embolisation $(n=1)$ and open surgical aneurysmorrhaphy $(n=2)$.

$\S$ Four stents and one MAL release by laparoscopy failed with five redo procedures: redo stenting $(n=2)$ and aortohepatic bypass $(n=3)$.

B a brachial haematoma, all of which were managed conservatively. There was no mesenteric ischaemia, or biliary, or pancreatic fistula. Median hospital stay was longer in group A than in group B ( 5 vs. 3 days; $p=.001$ ). After 30 post-operative days, all PDAAs were successfully excluded after both open repair and embolisation. All CAs treated by MAL release or bypass were patent; two CA stentings failed but were followed by successful conversion with laparoscopic MAL release.

\section{Midterm outcomes}

Two patients (6\%) in group A were lost to follow up after effective monitoring of five and six years, respectively. No patients in group $B$ were lost to follow up.

In group A, after a median follow up of 11 years (IQR 7 19 years), no PDAA recurrence was observed. All CAs following MAL release were patent without restenosis on DUS, and one of the eight aortohepatic bypass grafts occluded at five years.

In group B, PDAA recanalisation was observed in three patients 2.9 , 3.6, and 4.3 years after embolisation, respectively. Successful redo surgery was carried out in all cases with one redo embolisation, and two open surgical aneurysmorrhaphies. Five CA restenoses occurred, four of them between eight months and 4.3 years after CA stenting $(n=$ 4) and one at five years after MAL release by laparoscopy. Two of the CA restenoses were associated with PDAA recanalisation. The five patients received redo stenting $(n=$
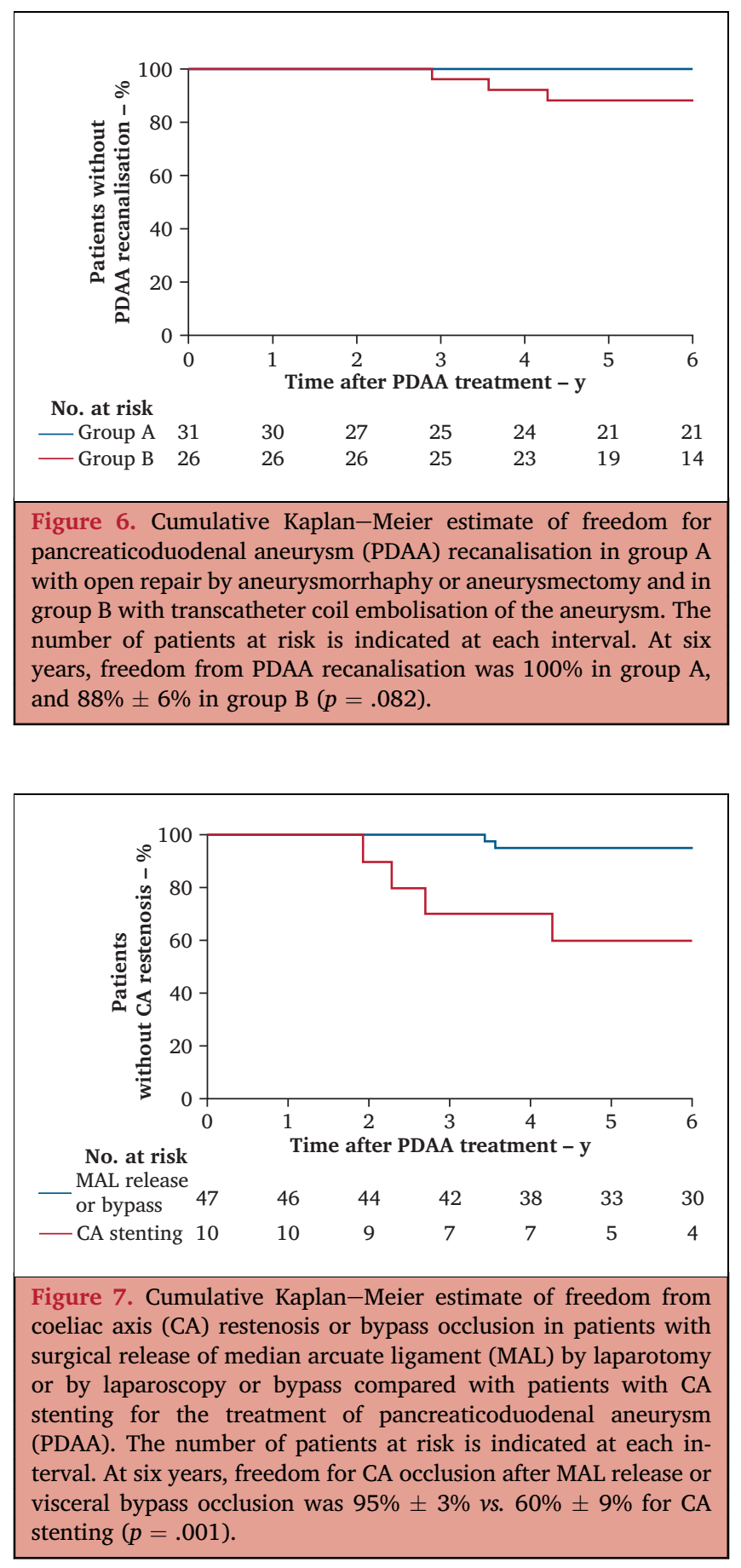

2) or aortohepatic bypass ( $n=3$ ), associated in two patients with aneurysmorrhaphy of a recanalised PDAA (Table 4).

At six years, Kaplan-Meier estimates of freedom from PDAA recanalisation were $100 \%$ in group $A$ and $88 \% \pm 6 \%$ in group $B(p=.082)$ (Fig. 6). For the same time period, estimates of freedom for CA restenosis/occlusion after MAL release or visceral bypass occlusion was $95 \% \pm 3 \%$ vs. $60 \%$ $\pm 9 \%$ for CA stenting ( $p=.001$ ) (Fig. 7). No PDAA ruptured during follow up. Six patients (10\%) died of unrelated causes during follow up. Overall survival at six years was $97 \% \pm 2 \%$. 


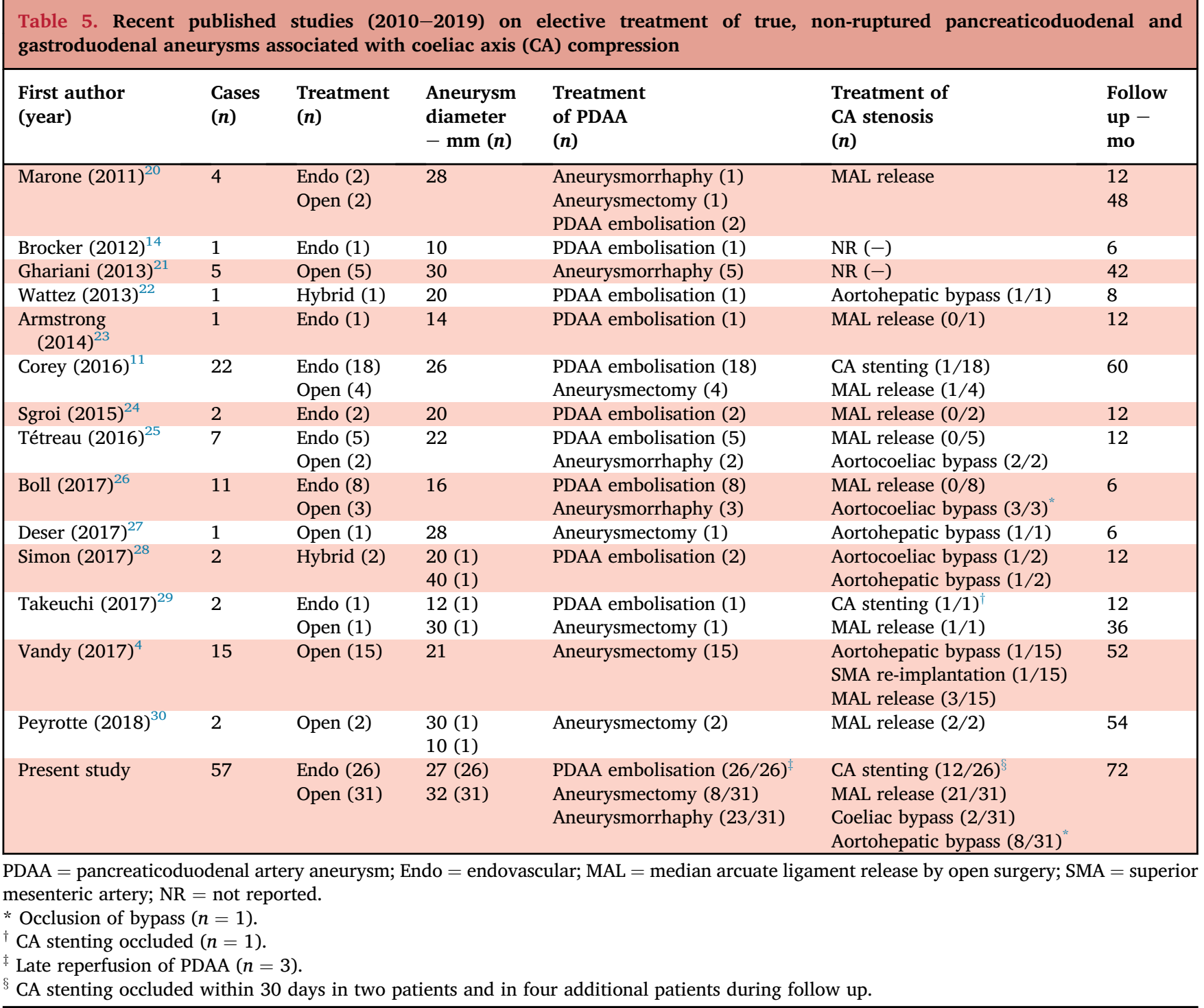

\section{DISCUSSION}

This multicentre study shows that open and endovascular treatment of PDAA yield excellent post-operative results, with zero mortality and low morbidity in both groups. However, midterm follow up showed differences, with late recanalisation of three PDAAs (11\%) following embolisation vs. none following open repair, and worrying results of $C A$ stenting, with a crude $50 \%$ occlusion rate $(n=6 / 12)$ at six years.

Since 2000 endovascular procedures have been performed for PDAA with increasing frequency. ${ }^{4}$ The increasing popularity of transcatheter PDAA embolisation is based on favourable comparison with open techniques in terms of post-operative complications, which can be as high as $19 \%$ for emergency open resection of PDAA vs. nearly none declared for endovascular techniques. ${ }^{14}$ There is no doubt that transcatheter PDAA embolisation is the preferred technique in urgent situations and in patients with severe comorbidities. ${ }^{8,15}$ However, endovascular treatment has some limitations. It exposes patients to the risk of late aneurysm reperfusion with the need for reintervention approaching $15 \%$ in the study by Barrionuevo et al. ${ }^{16}$ and $11 \%$ in this series. In addition, owing to complex arterial anatomy, embolisation is liable to be incomplete, with late recanalisation or extensive overflowing, with a risk of intestinal ischaemia or interruption of the anastomotic pathways related to low CA flow. ${ }^{8}$ No such complications were observed in the present series, where open surgical repair was used for all gastroduodenal aneurysms and in 29/44 anterior pancreaticoduodenal aneurysms, with preserved vascularisation of the pancreas and bowel, and a complementary coeliac or hepatic artery bypass in 10 patients without significant morbidity.

Conversely, all aneurysms of the posterior pancreaticoduodenal artery were treated by embolisation, which was preferred to open surgical repair with a Kocher 
manoeuvre and the attendant risk of pancreatic or biliary fistula. It is considered that the choice between transcatheter embolisation or open PDAA repair should be tailored according to the aneurysm's location and size.

Posterior pancreaticoduodenal artery aneurysms are most often easily accessible by catheterisation and should be embolised, except for large aneurysms of a broad based origin within millimetres of the SMA, which present the risk of small bowel and foregut structure ischaemia.

In this series, a MAL syndrome was present in all patients. These figures are comparable to those of Corey et al., ${ }^{11}$ who found it in $97 \%$ of CA stenoses in a relatively large series of 35 patients. Accumulating cumulative evidence from other studies has confirmed that $50 \%-80 \%$ of PDAAs are associated with CA compression by MAL, ${ }^{7,17-19}$ a fibrous arch that compresses the CA and leads (after years) to CA fibrosis and occlusion, as demonstrated in the 10 patients in this series in whom CA bypass was needed. Interestingly, while most PDAAs are degenerative, the most frequent cause of $C A$ occlusion is not degenerative but rather related to compression by MAL. Upon CA occlusion, haemodynamic changes in the pancreaticoduodenal arcades may be responsible for initiation, growth, and rupture of a PDAA. The haemodynamic hypothesis has been confirmed by Mano et al. ${ }^{19}$ using four dimensional magnetic resonance imaging. They found high retrograde flow with increased velocity and high shear stress in the pancreaticoduodenal and gastroduodenal arteries of patients with CA occlusion vs. controls. When associated with the results of clinical studies, ${ }^{7,17,18}$ these objective haemodynamic findings are important physiological arguments in favour of MAL release, even if clinical demonstration is difficult owing to the rarity of relevant cases.

A survey of contemporary series $(2010-2019)$ limited to elective treatment of true, non-ruptured PDAAs associated with CA occlusion was conducted (Table 5). In 14 recent publications, $^{4,11,14,20-30}$ excluding this one, 76 true PDAA cases were found, with 41 (54\%) transcatheter embolisation and 36 (46\%) open repair procedures. CA stenosis by MAL, which appeared in all of these patients, was treated in only 20 (29\%). This short contemporary survey shows that many authors question the need for CA release or revascularisation in patients with PDAA. They reject the aforementioned haemodynamic hypothesis on the basis of favourable case reports or short series of PDA aneurysms without CA release. $^{24,26,31,32}$ However, these results ought not to mask the need for critical understanding of PDA haemodynamics when treating these aneurysms. ${ }^{4,8,19}$

In the present series, open surgical release of MAL offered satisfactory long term results in all patients without fibrosis or CA occlusion ( $n=21$ ). In the remaining 10 patients, fibrosis due to long lasting compression by MAL required direct reimplantation of the CA on the coeliac aorta or revascularisation by an aortohepatic bypass leading to durable results, except for one patient with asymptomatic bypass occlusion discovered at the five year follow up CTA.

In group $B$, primary $C A$ stenting was carried out in 12 patients. The results, like those of several others, ${ }^{16,24,29,33-35}$ were disappointing, with two immediate failures and four CA restenoses or occlusions occurring between eight months and 4.3 years, with freedom from CA restenosis of only $60 \%$ at six years. It is recognised that these small numbers make it difficult to draw definitive conclusions, but a crude $50 \%$ rate of short term failures renders the use of stents in this indication questionable. Of note, PDAA recanalisation occurred in two patients with CA occlusion following stenting.

\section{Limitations of the study}

This study has two limitations, first its retrospective nature, and second the limited number of patients, despite multicentre recruitment. However, true PDAAs are rare and the majority of reports in the literature consist of only two or three cases or small series with a short follow up. Although not a randomised protocol, an attempt has been made to present the results of a consecutive series of patients with decent midterm follow up and balanced management according to the PDAA characteristics and the limitations of each technique.

\section{Conclusion}

The current data suggest that, under elective conditions, both open and endovascular treatment for PDAA yield excellent post-operative results, with few midterm recanalisations after PDAA embolisation. In this series, CA stenting yielded worrying results, with a significant number of early and midterm failures. This study also demonstrates that in an elective setting, open surgical treatment of PDAAs according to their topography and associated with MAL release or visceral revascularisation can be performed safely, with minimal risk.

\section{CONFLICT OF INTEREST}

None.

\section{FUNDING}

None.

\section{APPENDIX A. SUPPLEMENTARY DATA}

Supplementary data to this article can be found online at https://doi.org/10.1016/j.ejvs.2021.02.023.

\section{REFERENCES}

1 Stanley JC, Wakefield TW, Graham LM, Whitehouse Jr WM, Zelenock GB, Lindenauer SM. Clinical importance and management of splanchnic artery aneurysms. J Vasc Surg 1986;3:836-40.

2 Chaer RA, Abularrage CJ, Coleman DM, Eslami MH, Kashyap VS, Rockman C, et al. The Society for Vascular Surgery clinical practice guidelines on the management of visceral aneurysms. J Vasc Surg 2020;19:1-37.

3 De Perrot M, Berney T, Deleaval J, Buhler L, Mentha G, Morel P. Management of true aneurysms of the pancreaticoduodenal arteries. Ann Surg 1999;229:416-20.

4 Vandy FC, Sell KA, Eliason JL, Coleman DM, Rectenwald JE, Stanley JC. Pancreaticoduodenal and gastroduodenal artery aneurysms associated with celiac artery occlusive disease. Ann Vasc Surg 2017;41:32-40. 
5 Kadir S, Athanasoulis CA, Yune HY, Wilkov H. Aneurysms of the pancreaticoduodenal arteries in association with celiac axis occlusion. Cardiovasc Radiol 1978;25:173-7.

6 Suzuki K, Kashimura H, Sato M, Hassan M, Yokota H, Nakahara A, et al. Pancreaticoduodenal artery aneurysms associated with celiac axis stenosis due to compression by median arcuate ligament and celiac plexus. $J$ Gastroenterol 1998;33:434-8.

7 Pulli R, Dorigo W, Troisi N, Pratesi G, Innocenti AA, Pratesi C. Surgical treatment of visceral artery aneurysms: A 25-year experience. $J$ Vasc Surg 2008;48:334-42.

8 Bonardelli S, Spampinato B, Ravanelli M, Cuomo R, Zanotti C, Paro B, et al. The role of emergency presentation and revascularization in aneurysms of the peripancreatic arteries secondary to celiac trunk or superior mesenteric artery occlusion. J Vasc Surg 2020;72:46S-55S.

9 Coll DP, Ierardi R, Kerstein MD, Yost S, Wilson A, Matsumoto T. Aneurysms of the pancreaticoduodenal arteries: a change in management. Ann Vasc Surg 1998;12:286-91.

10 Guilbaud T, Ewald J, Turrini O, Delpero JR. Pancreaticoduodenectomy: secondary stenting of the celiac trunk after inefficient median arcuate ligament release and reoperation as an alternative to simultaneous hepatic artery reconstruction. World J Gastroenterol 2017;23:919-25.

11 Corey MR, Ergul EA, Cambria RP, Patel VI, Lancaster RT, Kwolek CJ, et al. The presentation and management of aneurysms of the pancreaticoduodenal arcade. J Vasc Surg 2016;64:1734-40.

12 Hongsakul K, Rookkapan S, Sungsiri J, Tubtawee T. A severe case of median arcuate ligament syndrome with successful angioplasty and stenting. Case Rep Vasc Med 2012;2012:129870.

13 van Petersen AS, Vriens $\mathrm{BH}$, Huisman $\mathrm{AB}$, Kolkman JJ, Geelkerken RH. Retroperitoneal endoscopic release in the management of celiac artery compression syndrome. J Vasc Surg 2009;50:140-7.

14 Brocker JA, Maher JL, Smith RW. True pancreaticoduodenal aneurysms with celiac stenosis or occlusion. Am J Surg 2012;204: 762-8.

15 Chivot C, Rebibo L, Robert B, Regimbeau JM, Yzet T. Ruptured pancreaticoduodenal artery aneurysms associated with celiac stenosis caused by the median arcuate ligament: a poorly known etiology of acute abdominal pain. Eur $J$ Vasc Endovasc Surg 2016;51:295-301.

16 Barrionuevo P, Malas MB, Nejim B, Haddad A, Morrow A, Ponce $\mathrm{O}$, et al. A systematic review and meta-analysis of the management of visceral artery aneurysms. J Vasc Surg 2019;70: 1694-9.

17 Huang YK, Hsieh HC, Tsai FC, Chang SH, Lu MS, Ko PJ. Visceral artery aneurysm: risk factor analysis and therapeutic opinion. Eur J Vasc Endovasc Surg 2007;33:293-301.

18 Tulsyan N, Kashyap VS, Greenberg RK, Sarac TP, Clair DG, Pierce G, et al. The endovascular management of visceral artery aneurysms and pseudoaneurysms. J Vasc Surg 2007;45: $276-83$.

19 Mano Y, Takehara Y, Sakaguchi T, Alley MT, Isoda H, Shimizu T, et al. Hemodynamic assessment of celiaco-mesenteric anastomosis in patients with pancreaticoduodenal artery aneurysm concomitant with celiac artery occlusion using flow-sensitive fourdimensional magnetic resonance imaging. Eur $J$ Vasc Endovasc Surg 2013;46:321-8.
20 Marone EM, Mascia D, Kahlberg A, Brioschi C, Tshomba Y, Chiesa R. Is open repair still the gold standard in visceral artery aneurysm management? Ann Vasc Surg 2011;25:936-46.

21 Ghariani MZ, Georg Y, Ramirez C, Lebied E, Gaudric J, Chiche L, et al. Long-term results of surgical treatment of aneurysms of digestive arteries. Ann Vasc Surg 2013;27:954-8.

22 Wattez H, Lancelevée J, Perot C, Massouille D, Chambon J-P. Compressive pancreaticoduodenal artery aneurysm associated with celiac artery stenosis. Ann Vasc Surg 2013;27:1187.e1-4.

23 Armstrong BA, Stadtlander KS, Grove MK. Pancreaticoduodenal artery aneurysm associated with median arcuate ligament syndrome. Ann Vasc Surg 2014;28:741.e1-5.

24 Sgroi MD, Kabutey NK, Krishnam M, Fujitani RM. Pancreaticoduodenal artery aneurysms secondary to median arcuate ligament syndrome may not need celiac artery revascularization or ligament release. Ann Vasc Surg 2015;29:122.e1-7.

25 Tétreau R, Beji H, Henry L, Valette PJ, Pilleul F. Arterial splanchnic aneurysms: presentation, treatment and outcome in 112 patients. Diagn Interv Imaging 2016;97:81-90.

26 Boll JM, Sharp KW, Garrard CL, Naslund TC, Curci JA, Valentine RJ. Does management of true aneurysms of peripancreatic arteries require repair of associated celiac artery stenosis? J Am Coll Surg 2017;224:199-203.

27 Deser SB, Demirag MK. Surgical treatment of inferior pancreaticoduodenal artery aneurysm with common hepatic artery revascularization. Ann Vasc Surg 2017;43:313. e9-313.e11.

28 Simon MA, Hedayati N, Pevec WC. Hybrid approach to aneurysms of the pancreaticoduodenal artery associated with occlusion of the celiac axis. Ann Vasc Surg 2017;44:414.e11-4.

29 Takeuchi Y, Morikage N, Samura M, Harada T, Yamashita O, Suehiro K, et al. Treatment options for celiac stenosis and pancreaticoduodenal artery aneurysms. Ann Vasc Surg 2017;41:281. e21-3.

30 Peyrotte A, Mariage D, Basqué P, Massalou D. Pancreaticoduodenal artery aneurysms due to median arcuate ligament syndrome: what we need to know. Surg Radiol Anat 2018;40: 401-5.

31 Reilly LM, Ammar AD, Stoney RJ, Ehrenfeld WK. Late results following operative repair for celiac artery compression syndrome. J Vasc Surg 1985;2:79-91.

32 Quandalle P, Chambon JP, Marache P, Saudemont A, Maes B. Pancreaticoduodenal artery aneurysms associated with celiac axis stenosis: report of two cases and review of the literature. Ann Vasc Surg 1990;4:540-5.

33 Ikeda O, Nakasone Y, Yokoyama K, Inoue S, Tamura Y, Yamashita Y. Simultaneous coil embolization and angioplasty using a self-expanding nitinol stent to treat pancreaticoduodenal artery aneurysms associated with celiac artery stenosis. Acta Radiol 2013;54:949-53.

34 Grotemeyer D, Duran M, Iskandar F, Blondin D, Nguyen K, Sandmann W. Median arcuate ligament syndrome: vascular surgical therapy and follow-up of 18 patients. Langenbecks Arch Surg 2009;394:1085-92.

35 Delis KT, Gloviczki P, Altuwaijri M, McKusick MA. Median arcuate ligament syndrome: open celiac artery reconstruction and ligament division after endovascular failure. J Vasc Surg 2007;46: 799-802. 